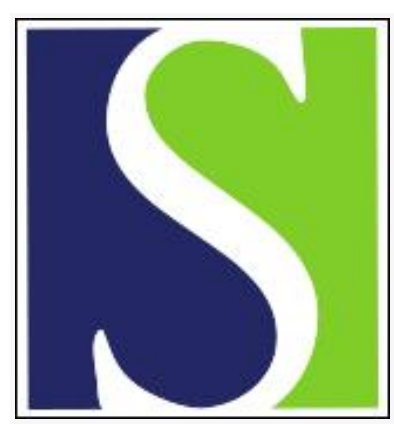

Scand J Work Environ Health 1984;10(6):473-479

https://doi.org/10.5271/sjweh.2320

Issue date: Dec 1984

Pleural changes and exposure to fibrous minerals.

by Hillerdal $\mathrm{G}$

This article in PubMed: www.ncbi.nlm.nih.gov/pubmed/6100140

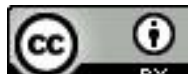

This work is licensed under a Creative Commons Attribution 4.0 International License 


\title{
Pleural changes and exposure to fibrous minerals
}

\author{
by Gunnar Hillerdal, MD
}

\begin{abstract}
HILLERDAL G. Pleural changes and exposure to fibrous minerals. Scand $J$ Work Environ Health 10 (1984) 473-479. The pleura is a main target for various reactions related to asbestos exposure. However there are great radiological and clinical differences between the various reactions, and there is also increasing evidence that they have different prognoses. The main reactions are pleural plaques on the one hand and acute pleurisy and diffuse pleural fibrosis on the other. In a population with a low mesothelioma risk, the anthophyllite-exposed population of Northern Karelia in Finland, there are very few reactions of the second type, while plaques are very common. In Turkey, where the exposure is to erionite, the mesothelioma level is extremely high, and reactions of type two are very common in the exposed population. Thus it seems that careful discrimination of the various pleural changes can have prognostic value. There are also indications that plaques do not have any relation to a disturbed immunologic system, while pleurisy and diffuse pleurisy have.
\end{abstract}

Key terms: acute pleurisy, asbestos, diffuse pleural fibrosis, mesothelioma, pleural plaques, prognosis.

The pleura is one of the main target organs for inhaled mineral fibers. The first large series of pleural changes to be described in connection with exposure to minerals came in the 1940 s among talc workers, who had what is now recognized as fairly typical parietal pleural plaques $(18,19)$. It is currently believed that it was not the talc, but rather the asbestos that contaminated it, that caused the plaques. In 1960, Kiviluoto (14) published his findings from an area of Finland where asbestos occurred in the soil and where a large portion of the adults had calcified pleural plaques in their chest radiographs. Since then, there have been many areas in Europe and other places for which such endemic plaques have been described.

In 1965 Wagner \& co-workers (22) published their findings from South African asbestos mines and the dramatic increase of pleural mesotheliomas there, and since then the connection between mesotheliomas and exposure to mineral fibers has been definitely established.

The last decade has shown that mineral fibers other than asbestos, notably the mineral fiber called erionite, which is unrelated mineralogically to asbestos, can cause ail the pleural changes described for exposure to asbestos, including mesothelioma. These reports came from Turkey where Professor Baris has made some remarkable studies (3). Erionite is the fibrous form of a large mineral family called zeolites. The fiber is formed during very special conditions in volcanic areas.

\footnotetext{
1 Department of Lung Medicine, University Hospital, Uppsala, Sweden.
}

Reprint requests to: Dr G Hillerdal, Department of Lung Medicine, University Hospital, S-750 14 Uppsala, Sweden.
There have been extensive discussions regarding the risk of other mineral fibers, including man-made ones, but the gathered data are as yet inconclusive, even if strong suspicions remain for some of them.

There is today general agreement that at least a major part of the pathogenicity of mineral fibers is due to their physical shape, and experimentally it has been established that the smaller the diameter and the longer the fiber, the more dangerous it is (21). The most dangerous of the fibers so far investigated in vitro is in fact erionite, which has a very high length:diameter ratio. It should in this context be stressed that the zeolites, to which erionite belongs, form a very large group of minerals which is of great commercial use and the majority of which is not fibrous and thus, as far as is known, is completely harmless.

The second most dangerous fiber is crocidolite, which is also long and thin. Specially constructed glass fibers with diameters and lengths similar to those of erionite and crocidolite are effective carcinogenic agents in the laboratory (21), but it should be remembered that other factors such as durability in biological tissue are also of great importance in humans.

Even if in many countries asbestos is now strictly controlled or even banned, the incidence of pleural changes (and other asbestos-related diseases) is high due to the fact that there is a delay of at least one and often more decades from the time of exposure until the disease or pathological findings become manifest. Thus new cases will appear well into the next century.

There is a large number of studies going on regarding mineral fibers and their effects on the pleura and other organs. I would like to raise some points which I think are important and will lead to interesting findings in the future. 


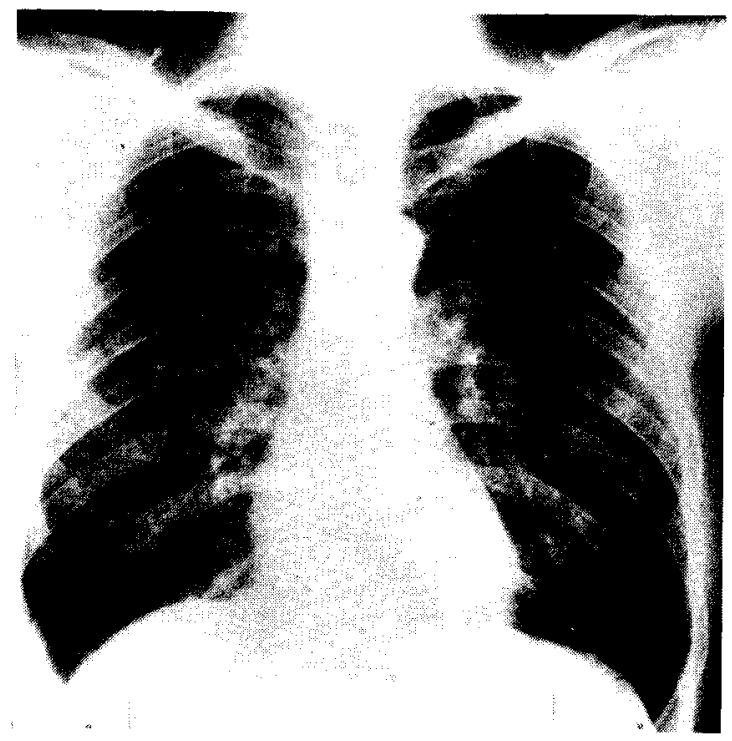

A
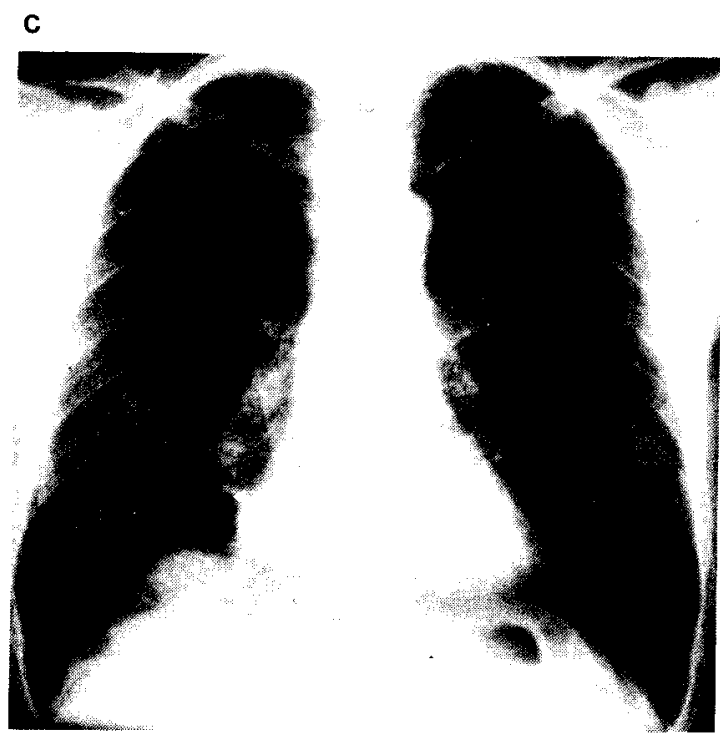

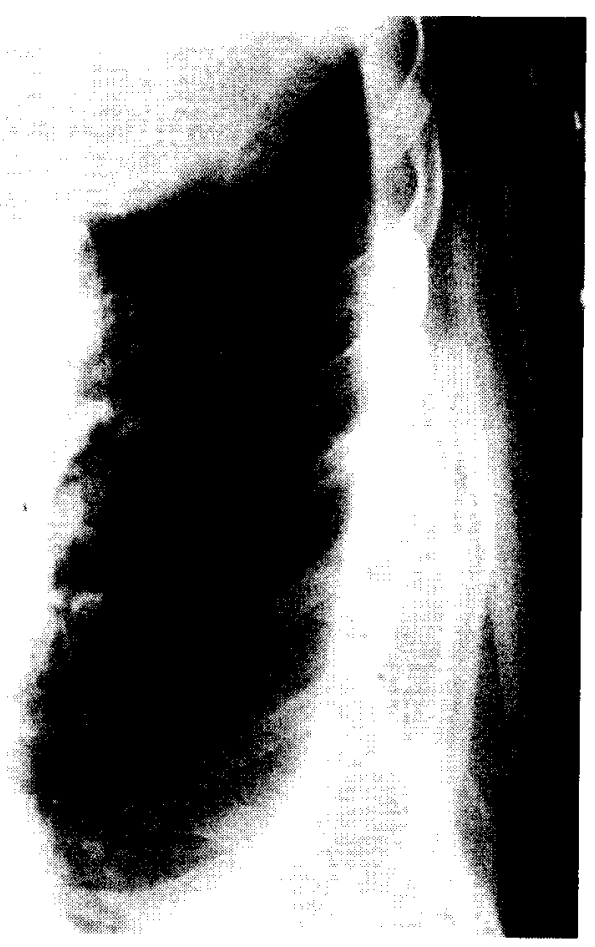

B

Figure 1. Asbestos pleurisy with remnants. $(A=$ frontal view in 1969 - right-sided small exudate [visible better in B (right side downwards)], $\mathrm{C}=$ frontal view in 1982 - pleural strands basally right, small plaques left)

these groups, and thus possibly the type of pleural change has some prognostic importance in this respect.

Third, the pathogenesis must be different, and there are indications that immunologic factors are more important for some pleural affections than for others.

Thus this paper will first deal briefly with the various benign changes and their radiological differentiation and natural history. It will then present some epidemiologic data from various countries, and finally some short comments will be made on immunologic factors. 

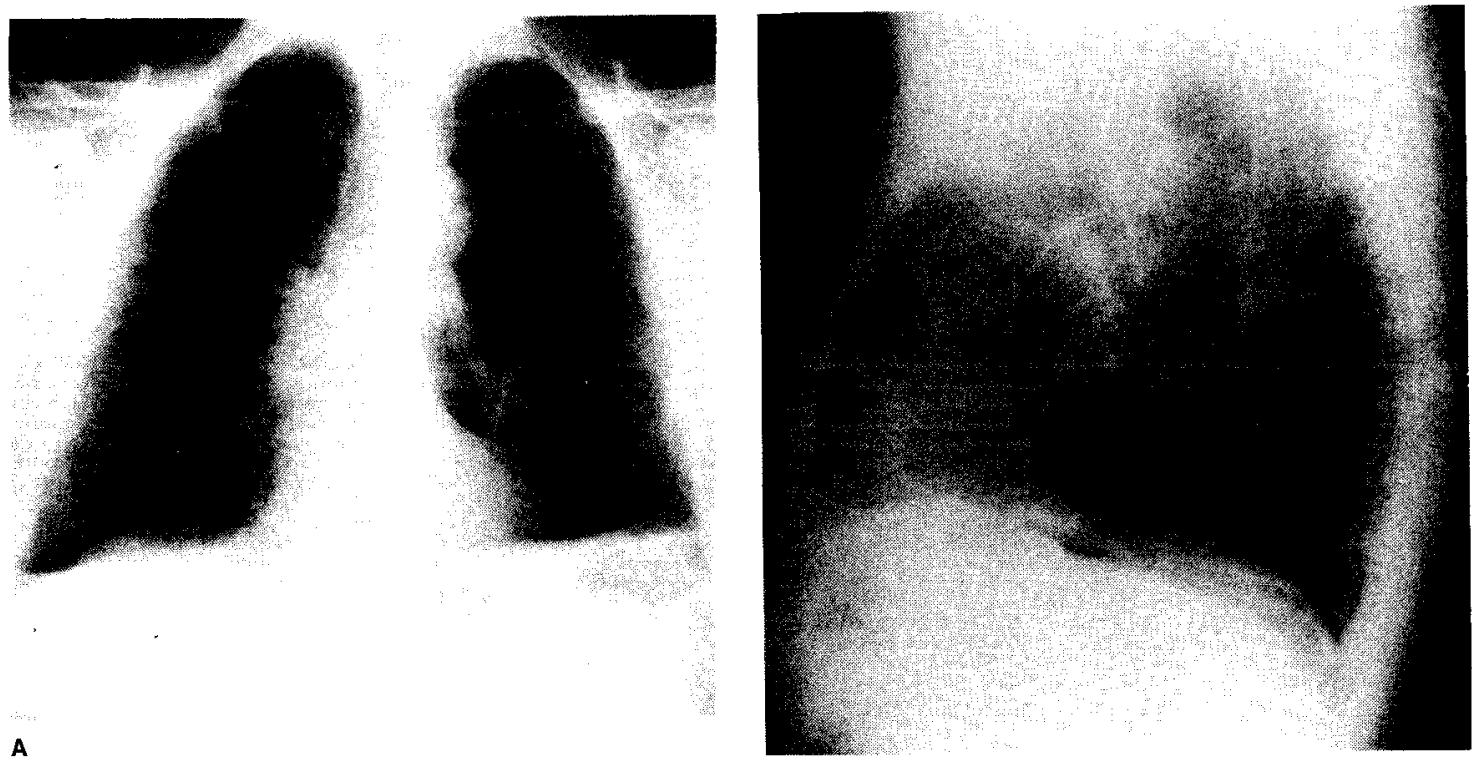

A

B
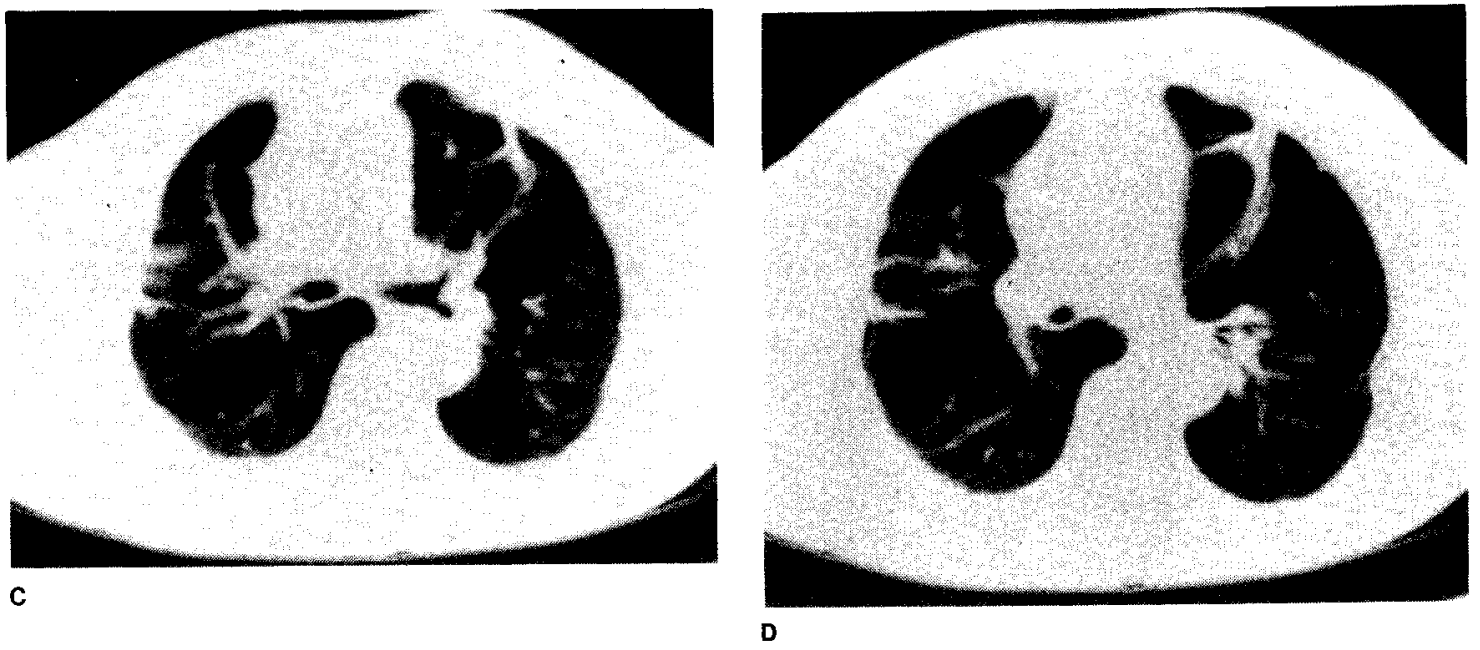

E

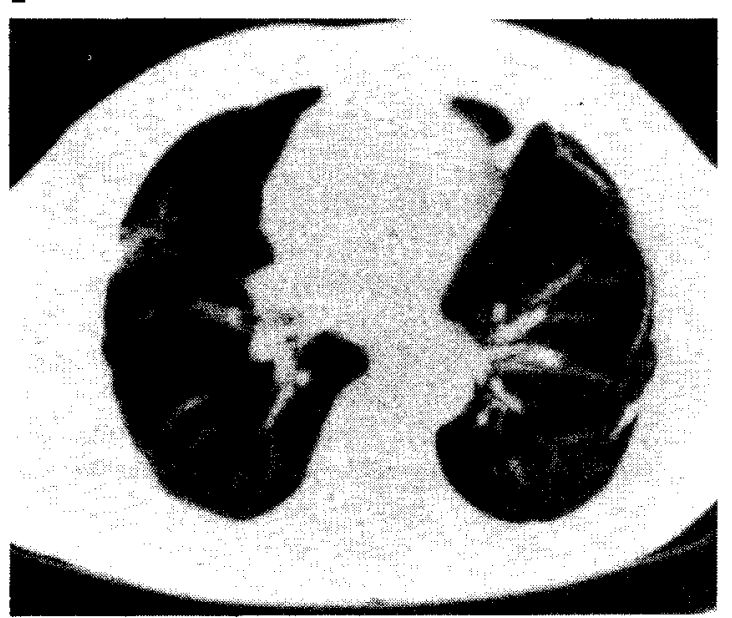

Figure 2. Bilateral pleural fibrosis $(A=$ frontal view, $B=$ lateral view). Note the rounded costophrenic angles and the pleural strands in the computer tomographic scans, at different levels, in $C$ to $E$. Note the surprisingly thick fibrous strands which penetrate into the lung from the thickened pleura. 

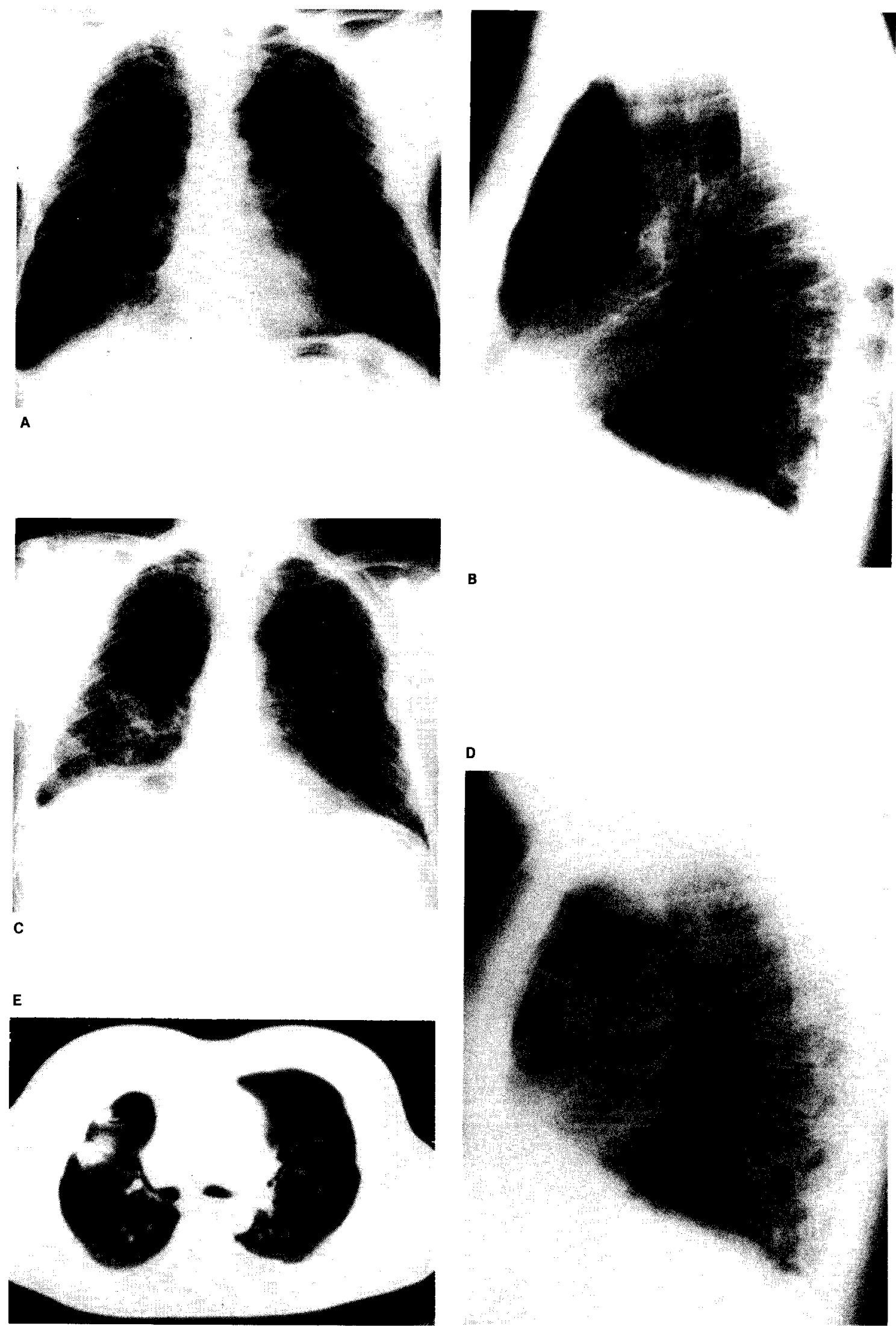

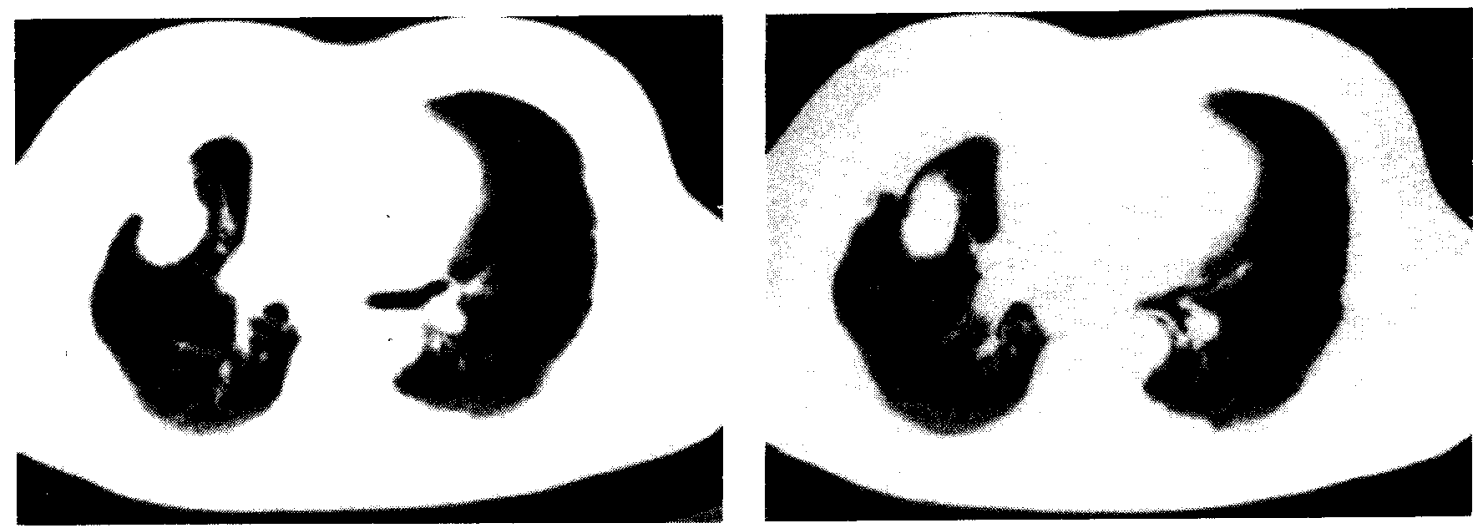

$F$

G

Figure 3. Pleural fibrosis developing into rounded atelectasis $(A=$ frontal view, $B=$ lateral view, $C \& D=$ pleural strands and rounded costophrenic angle right three years later). Note the rounded formation on the right side, situated in front of the heart at the lateral view in the computer tomographic scans in $\mathrm{E}$ to $\mathrm{G}$. Note the similarities between figure $2 \mathrm{C}$ and figure $3 \mathrm{E}$. Bronchoscopy twice and fine needle puncture three times yielded inflammatory cells only.

\section{Radiological pleural changes related to exposure to mineral fibers}

\section{Pleural plaques}

Pleural plaques are situated exclusively on the parietal pleura. They develop slowly and are radiologically visible only after two or more decades. The costodiaphragmatic angle is never affected $(1,2,4,8)$. In a scan made by computer tomography, the very sharp demarcation from normal lung is clearly seen. There are never any adhesions between the pleural layers. The plaques gradually enlarge and can calcify. The most common sites are laterally and dorsally on the chest wall and on the diaphragm.

The clinical importance of pleural plaques is mainly that they are an indication of exposure to some mineral fiber and thus that there is a risk of increased morbidity from other diseases related to exposure to that particular fiber.

\section{Mineral fiber pleurisy}

A person exposed to asbestos or erionite can develop a sudden pleural exudate. This pleurisy is often surprisingly lacking in symptoms, and the exudate can be an unexpected finding when a chest radiograph is taken for some unrelated reason. Usually the exudate is less than 11 , but larger amounts can also be found (figure 1).

The exudate can be hemorrhagic, despite the fact that it is benign, but it can also be lymphocytic, have eosinophilic features, or be of any type. Thus there are no pathognomonic findings, and the diagnosis is one of exclusion, the most important differential diagnoses being malignancy or tuberculosis. After some months the exudate tends to disappear, usually leaving remnants but sometimes without traces. There is a high tendency towards recurrence on the same or other side $(6,17,20)$.
If there are remnants, they are adhesions and thickenings of the pleura. The simplest form is a rounding of the costodiaphragmatic angle. If more advanced, there is also a diffuse thickening of the pleura sometimes surrounding the whole lung. Typically, there are fibrous strands going into the lung from the thickened pleura, sometimes going very deep into the parenchyma and occasionally traversing the whole lung (figure 2). The best method to illustrate this phenomenon is computer tomography, but it is usually not necessary.

A special variant of these changes is the so-called rounded atelectasis, where fibrotic strands have contracted and "caught" the lung, causing bending of some small bronchi with consequent atelectasis of a peripheral part of the lung (figure 3). Radiologically one cannot distinguish between an atelectatic lung and fibrous tissue. Differentiation from a malignant tumor can be a problem also.

Since the exudate is often free of symptoms, the described remnants are often found in an investigation without any exudate having ever been diagnosed. Most probably, such an episode has occurred earlier anyway, but it is of course difficult to prove.

Thus, for the purpose of the next part of this paper, two different types of benign pleural reactions have been defined - pleural plaques and mineral fiber pleurisy with remnants. It should be stated that these definitions are not generally accepted by all researchers, at least not yet.

\section{Epidemiologic data on different mineral fibers and radiological pleural changes}

So far, only limited epidemiologic data are available on the subject of different mineral fibers and radiological pleural changes. I will give the results of my 
Table 1. Pleural changes related to mineral fibers and risk of mesothelioma in various populations.

\begin{tabular}{|c|c|c|c|c|c|}
\hline \multirow{2}{*}{ Place } & \multirow{2}{*}{$\begin{array}{l}\text { Total number } \\
\text { of persons }\end{array}$} & \multicolumn{3}{|c|}{ Percentage with sequelae of pleurisy } & \multirow{2}{*}{$\begin{array}{l}\text { Risk of } \\
\text { mesothelioma }\end{array}$} \\
\hline & & Unilateral & Bilateral & Total & \\
\hline \multicolumn{6}{|l|}{ Turkey } \\
\hline $\begin{array}{l}\text { Erionite } \\
\text { Asbestos } \\
\text { Reference village }\end{array}$ & $\begin{array}{l}549^{b} \\
466^{b} \\
382\end{array}$ & $\begin{array}{c}23.2 \\
18.0 \\
1.6\end{array}$ & $\begin{array}{l}9.0 \\
7.0 \\
0\end{array}$ & $\begin{array}{l}32 \\
25 \\
1.6\end{array}$ & $\begin{array}{l}\text { Very high } \\
\text { High }\end{array}$ \\
\hline $\begin{array}{l}\text { Sweden } \\
\text { Uppsala }\end{array}$ & $1053^{b}$ & & & 14.5 & Average \\
\hline \multicolumn{6}{|l|}{ Finland } \\
\hline $\begin{array}{l}\text { Anthophyllite } \\
\text { Reference village }\end{array}$ & $\begin{array}{l}773^{b} \\
1073\end{array}$ & $\begin{array}{l}4.7 \\
6.5\end{array}$ & $\begin{array}{l}0.9 \\
0.7\end{array}$ & $\begin{array}{l}5.0 \\
7.2\end{array}$ & None \\
\hline
\end{tabular}

a Reference villages without mineral fiber exposure.

bersons with pleural changes only.

own studies made in cooperation with a number of other researchers and then give some hints of what can be concluded from other literature.

Studies using the described classification have been made in three countries - Finland, Turkey, and Sweden (table 1). The Finnish data (12) are from the endemic area first described by Kiviluóto, where anthophyllite asbestos occurs in the ground and where a sizeable portion of the adults have calcified pleural plaques (14). From Turkey, data are available from villages where asbestos has been used for whitewashing houses and other purposes and another village where erionite has been found as the cause of pleural changes (11). The Swedish data come from findings from chest radiographs. Most of the subjects have been occupationally exposed to asbestos, mainly chrysotile, but also to some extent to amphiboles $(8,9)$.

As seen from table 1, the risk of mesothelioma seems to correlate fairly well with the relative frequency on remnants of pleurisy in the populations. This finding should of course be confirmed by further studies, for instance, in South Africa, where there is a high incidence of mesothelioma in the crocidolite mines, in Canada, where the mesothelioma incidence is low in the chrysotile mines, etc.

Confirming results from the literature are hard to find since it is rarely clearly described what is meant by pleural changes. However, in reports from South Africa (20) and from Australia (where there has also once been a crocidolite mine in use) (7), it seems clear that asbestos pleurisies and remnants thereof are not rare.

\section{Pathogenesis and immunology}

The slowly developing pleural plaques seem to point to a low-grade continuous irritation. The sudden development of the pleural exudate, however, points to some trigger mechanism probably caused by immunologic stimulation. The continued activity and recurrences also have similarities to the exudates which can be seen for instance in rheumatoid arthritis and other so-called autoimmune disease.

Immunologic disturbances in asbestos-exposed persons have been reported in a large number of papers. There is a stimulation of $B$ cells with increased levels of gammaglobulins and such autoantibodies as the antinuclear factor, the rheumatoid factor, etc $(13,15,16)$. On the other hand the T lymphocytes are depressed and cause a disappearance or depression of the delayed cutaneous hypersensitivity (5). In vitro, a large number of immunologic aberrations has also been described. However, the clinical importance of these changes has yet to be shown.

One very simple test, erythrocyte sedimentation rate (ESR), is extensively used in clinical practice, but it is not clearly understood. In the Uppsala material, it was found that some of the patients had an unexplained consistently high rate. When analyzed, these patients usually fell into the category "asbestos pleurisy and remnants." A prospective study showed, with high statistical significance, that the erythrocyte sedimentation rate of patients with only pleural plaques was in the normal range, while those who had bilateral remnants of pleurisy showed a pathologically high mean value (10). The exact mechanism of this phenomenon is unclear, but it should probably be taken as yet another indication that immunologic factors are involved to a larger extent in these changes than they are in changes among those who have only pleural plaques.

Thus, there remains a number of highly fascinating questions regarding the pleural changes caused by mineral fibers. Future studies discriminating between the various pleural lesions and correlating mineralogical and immunologic findings will probably yield interesting results.

\section{References}

1. Anton HC. Multiple pleural plaques. $\mathrm{Br} \mathrm{J}$ Radiol 40 (1967) 685-690.

2. Anton HC. Multiple pleural plaques: Part II. $\mathrm{Br} \mathrm{J}$ Radiol 41 (1968) 341-348. 
3. Baris YI, Sahin AA, Ozesmi M, Kerse I, Ozen E, Kolacan B, Altinörs M, Göktepeli A. An outbreak of pleural mesothelioma and chronic fibrosing pleurisy in the village of Karain/Urgüp in Anatolia. Thorax 33 (1978) $181-192$.

4. Becklake MR. State of the art: Asbestos-related diseases of the lung and other organs: Their epidemiology and implications for clinical practice. Am Rev Respir Dis 114 (1976) 187-227.

5. de Shazo RD, Nordberg J, Baser Y, Bozelka B, Weill $\mathrm{H}$, Salvaggio J. Analysis of depressed cell-mediated immunity in asbestos workers. J Allergy Clin Immunol 71 (1983) 418-424.

6. Eisenstadt HB. Asbestos pleurisy. Dis Chest 46 (1964) 78-81.

7. Elder JL. A study of 16 cases of pleurisy with effusions in ex-miners from Wittenom Gorge. Aust $\mathrm{N} \mathrm{Z} \mathrm{J} \mathrm{Med}$ 2 (1972) 328-329.

8. Hillerdal G. Pleural plaques: Occurrence, exposure to asbestos, and clinical importance. Acta Univ Ups 363 (1980) $1-227$.

9. Hillerdal G. Asbestos-related chest X-ray changes and diseases in the county of Uppsala, Sweden. Arch Immunol Ther Exper 30 (1982) 301-307.

10. Hillerdal G. Asbestos-related pleuropulmonary lesions and the erythrocyte sedimentation rate. Thorax 39 (1984) 752-758.

11. Hillerdal G, Baris YI. Radiological study of pleural changes in relation to mesothelioma in Turkey. Thorax 38 (1983) $443-448$.

12. Hillerdal G, Zittin A, van Assendelft A, Kuusela T. Rarity of benign asbestos pleurisy among persons ex- posed to Finnish anthophyllite asbestos. Thorax 39 (1984) 608-611.

13. Huuskonen MS, Räsänen JA, Härkönen $H$, Asp $S$. Asbestos exposure as a cause of immunological stimulation. Scand J Respir Dis 59 (1978) 326-332.

14. Kiviluoto R. Pleural calcification as a roentgenologic sign of nonoccupational endemic anthophyllite asbestosis. Acta Radiol Suppl 194 (1960) 1-67.

15. Lange A. An epidemiological survey of immunological abnormalities in asbestos workers: I Nonorgan and organ specific autoantibodies. Environ Res 22 (1980) $162-175$.

16. Lange A. An epidemiological survey of immunological abnormalities in asbestos workers: II Serum immunologlobulin levels. Environ Res 22 (1980) 176-183.

17. Navratil M, Dobias J. Development of pleural hyalinosis in long term studies of persons exposed to asbestos dust. Environ Res 6 (1973) 455-472.

18. Porro FW, Patton JR, Hobbs AA. Pneumoconiosis in the talc industry. Am J Radiol 47 (1942) 507-524.

19. Siegal W, Smith AR, Greenburg L. The dust hazard in tremolite talc mining, including roentgenologic findings in talc workers. Am J Radiol 49 (1943) 11-29.

20. Sluis-Cremer GK, Webster I. Acute pleurisy in asbestos exposed persons. Environ Res 5 (1972) 380-392.

21. Stanton MF, Wrench C. Mechanisms of mesothelioma induction with asbestos and fibrous glass. J Natl Cancer Inst 48 (1972) 797-821.

22. Wagner C, Sleggs CA, Marchand P. Diffuse pleural mesothelioma and asbestos exposure in the North Western Cape Province. Br J Ind Med 17 (1968) $260-271$. 